\title{
Growth is Disappearing and May Not Recover in the Medium Run
}

\section{BY VLADIMIR GLIGOROV}

COUNTRIES In TRANSition in Central, Eastern, and South Eastern Europe (CESE) have been hit hard by the global crisis. Though there was some stabilization at the turn of the first to second quarter of this year (2009), the risks of further deterioration in some of the countries are still quite high (Gligorov, Poeschl, and Richter 2009). These risks are mainly connected with the stability of the financial sector, with falling public revenues, and with slow revival of demand in the European Union which is the principal market for CESE exports. There is also a need to rethink the growth model because a return to
- the status quo ante does not seem realistic, at least not in the medium term.

\section{Integration and contagion}

MOST OF THE CESE ECONOMIES are small, open, and quite integrated with the European Union (EU). These include the so called New Member States (NMS) that joined the EU in 2004 and 2007 , two of which have recently entered the euro area (Slovenia and Slovakia), as well as the countries in Southeast Europe that have yet to join the EU (so called Future Member States, FMS, or candidate and potential candidate countries,

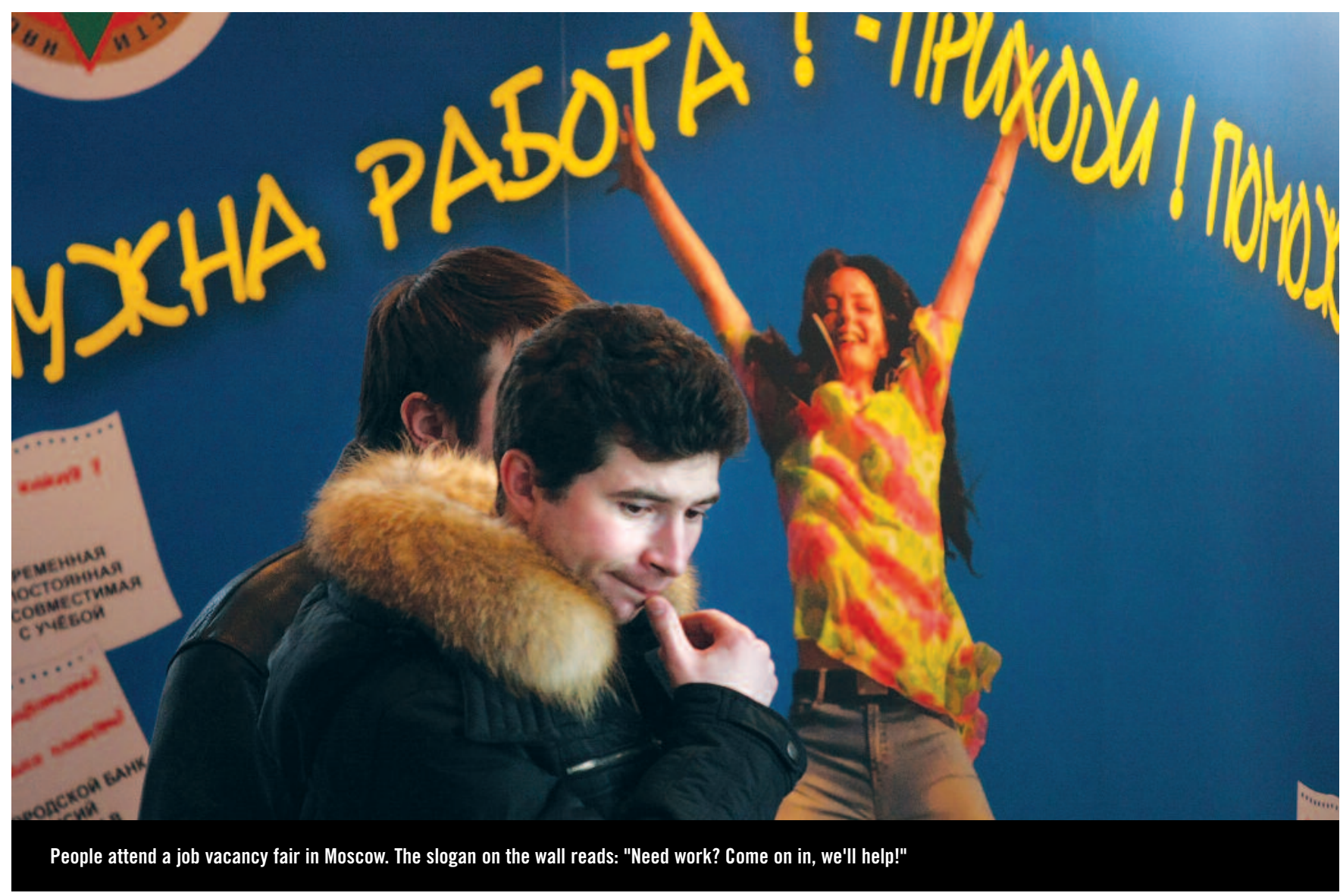


which include Turkey). Countries farther to the east, for example, Ukraine, Belarus, and in particular Russia are either larger countries or less integrated with the EU or both.

Integration has been a mechanism of both propagation and mitigation of crisis. Because of the high level of trade integration, the crisis has led to a sharp decline in both exports and imports. In addition, financial integration is a source of instability, even though their domestic financial sectors may be sound. Thus, countries that are more integrated with the EU have suffered more from the crisis. On the other hand, these countries are also better positioned to profit from the various measures introduced in the EU to support stability and spur recovery. As long as these measures stimulate trade and stabilize the financial system that has positive consequences for the more integrated CESE countries because it supports their exports to the EU markets.

A more fundamental problem of deep integration is that it leads to a strategy of growth that implies high and persistent external imbalances: the main indicator being the current account deficit. This could be called a neoclassical growth model. In the initial phases, foreign investments rush in to profit from high productivity growth in capital scarce economies and, later on, exports increase sufficiently to cover the trade deficits: in the process, there is convergence growth, that is, when growth in less developed countries is faster than in the more developed ones. The real and nominal exchange rates adjust, basically appreciate, in order to support that process. In the end, the remaining current account deficit reflects the income balance, where the profits and dividends of the foreign investors are recorded.

Countries in transition can be classified by the stage in which they find themselves in this process. Roughly, EU member states (NMS) have mostly balanced trade by now

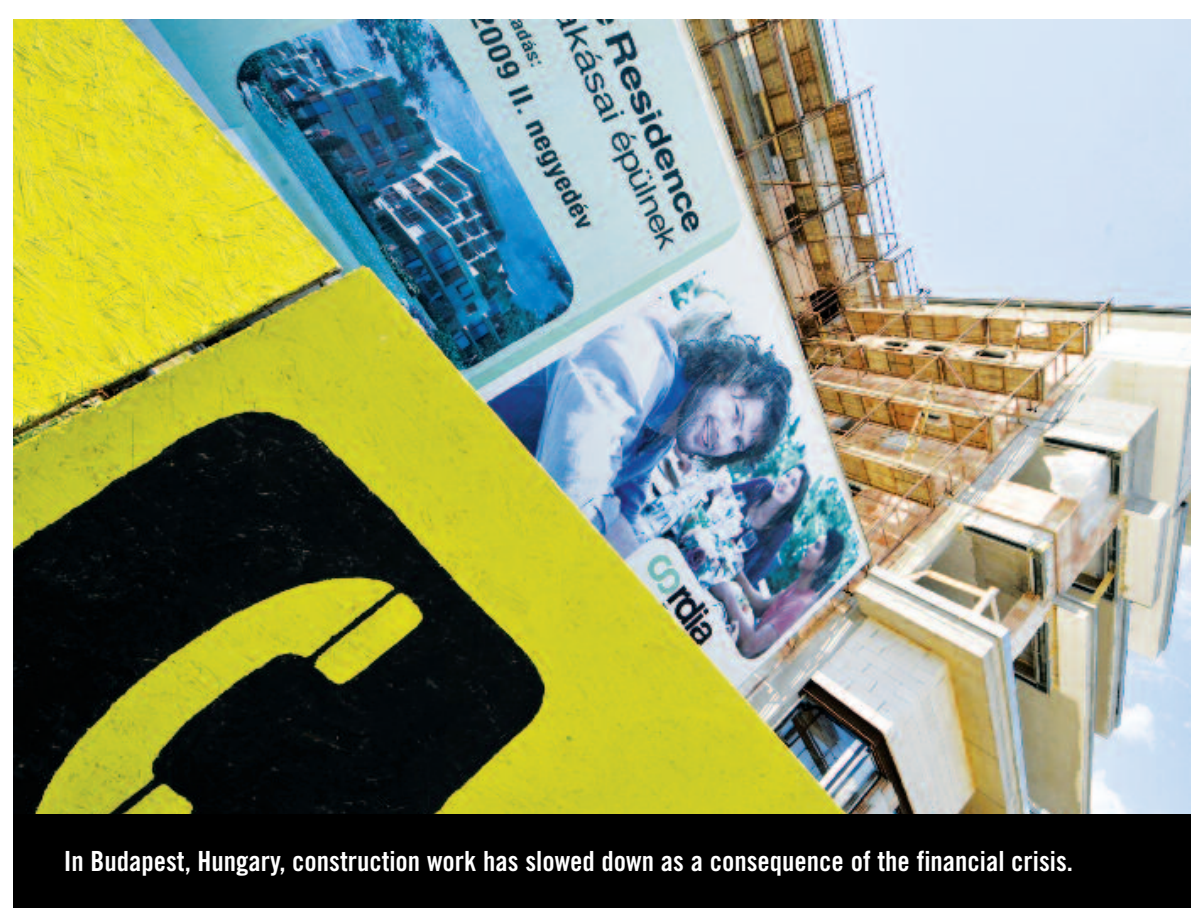

(though not the income account), while countries to the southeast (FMS) have more pronounced, or very pronounced, trade deficits. Countries farther to the east are less integrated and also depend more on export specialization-they export mainly oil, gas, metals, and raw materials-and thus have different balance of payments structures reflecting a somewhat different model of growth and development.

In the group of countries with current account deficits, the lack of demand for their exports and the declining availability of foreign financing work together to produce sharp and in some cases disastrous recessions. Negative growth rates vary between minus almost 20 percent in some of the Baltic countries to minus 1 percent in some Balkan countries (Poland being an exception with close to 1 percent growth so far this year). Overall, more open countries (in terms of the exports to GDP ratio) with trade and income account deficits, such as the Baltic countries, are doing worse, while more closed economies such as Poland, with less of a deficit in their income accounts (for example, the FMS), are experiencing milder recessions. On the other hand, economies that are more open are better placed to benefit from fiscal and other measures that are supportive of trade and may also have more stable, though not risk-free, financial systems.

\section{Risks and sustainability}

EXCHANGE RATE REGIMES and fiscal policies account for much of the change in risks and in the assessment of sustainability of macroeconomic balances. Given that the main vulnerability is the external imbalance, the adjustments of the exchange rates have to be expected, as are the limitations on the activism of fiscal policy, because widening fiscal deficits can spill over into higher imports.

The risks to the stability of exchange rates are significant, though the general direction for countries with current account deficits is one of exchange rate depreciation. However, the distribution of risks depends to a large extent on the exchange rate regime: countries using the euro, those with fixed exchange rates and those with flexible rates have different financial and real consequences.

In general, countries with flexible exchange rates have seen sharp nominal devaluations, which have also led to weaker but still significant real exchange rate devaluations (for example, Poland, the Czech Republic, Hungary, Romania, Serbia, and Turkey). This has had some cushioning effect for the tradable and the real sectors generally, but in certain cases has increased financial risks (for example, 
Hungary, Romania, and Serbia). Countries with fixed exchange rates, on the other hand, have struggled to stabilize their financial sector, with increasing risks in the real sector in some cases (for example, Baltic countries and Croatia). In these cases, real exchange rate adjustment has to come about through deflation which introduces huge risks in the real economy. Finally, economies that are inside the euro area (Slovakia and Slovenia) or that use the euro (for example, Montenegro and Kosovo) have additional difficulties to engineer real exchange rate adjustments because they tend to resort to fiscal stimuli which, although they work against the deflationary tendencies, put their tradable sectors at risk.

Thus, to the extent that the financial sector has been stabilized for the moment, the remaining risk has to do with the adjustment of the real economy, which may prove to be rather more difficult in those countries with fixed exchange rates (or hard pegs, for example, currency boards) in the short run, due to the problems that deflation brings, and rather more difficult for countries using the euro in the medium run, due to loss of competiveness. Countries with flexible exchange rates, however, may run into liquidity problems in the short run, because of worsening balance sheets in the financial, household and the corporate sectors, but should be in a better position to take advantage of the increase in external demand in the medium run.

In some countries, monetary policy is not completely impotent, though only Russia has enough room to manoeuvre. When it comes to fiscal policy, however, some countries are in a better position than others. In general, transition economies have had relatively lax fiscal constraints in the last decade or so because of their high growth rates. So, even with persistent fiscal deficits, debt to GDP ratios tended to decline. This was also supported by declining interest rates. Thus, irrespective of fiscal deficits, sustainability of fiscal balances was not an issue: the real limitation on fiscal expansion was the sustainability of the current account because of the steady accumulation of foreign debt, mostly by the private sector. Because credit was readily available at affordable prices, many countries ran pro-cyclical fiscal policies even in the face of rising current account deficits and surging private debt. As a consequence, fiscal policies in the crisis have also had to be pro-cyclical and fiscal positions in many cases now seem unsustainable: with rising interest rates, rising fiscal deficits, and worsening growth prospects, public debt to GDP ratios tend to increase without limit.

Sustainability of fiscal balances does not look much better even in countries with quite low levels of public debt, for example, the Baltic countries. This is because credit has dried up, depression has set in, and fiscal risks have increased very rapidly. These countries are trying to cut public expenditures dramatically, but if that leads to mass bankruptcies in the household and the corporate sectors, public obligations will shoot up immediately and fiscal balances will be unsustainable. This is what is meant by fiscal risks. A minority of countries have stuck to countercyclical policies and so can resort to fiscal stimuli in times of crisis. These include, for example, the countries in the euro area, as well as Bulgaria, the Czech
Republic and Montenegro, Russia, and some other oilexporting countries. But overall, fiscal expansion is not an option because of growing risks to exchange rates, nominal or real, and unsustainable fiscal balances.

\section{Savings and exports}

IF THE PROGESS OF DELEVERAGING GONTINUES for some time, the possibility of going back to the neoclassical model of growth may be called into question. If foreign financing remains unavailable or expensive, what is the alternative model of growth? Clearly, domestic savings will have to increase. At the moment, trade deficits are shrinking fast as are current account deficits. Although this is mostly the consequence of the decline in consumption, it is not altogether clear that savings are increasing, which would have to happen for investments to increase as well. Finally, growth will have to be supported by exports and by the expansion of the tradable sector in general. The latter depends on the recovery of demand in the EU, which will take some time. Growth based on domestic demand is possible in larger countries like Russia, Ukraine or Poland, but smaller economies cannot normally rely on domestic markets. In that context, adjustment of the real exchange rate is crucial, as mentioned earlier in this article.

There are, however, some limitations on the growth of savings. Most countries in transition are demographically quite old and employment rates are relatively low (European Commission 2009). In addition, public sector and social security reforms have not led to significant increases in savings rates. An increase in public savings does not seem realistic, while private savings increases are limited. Finally, profitability has declined and it may take some time before it improves; thus incentives to invest will be weak. As a consequence, there are significant risks that the recovery will take some time and growth will be weak in the medium run: in some cases, prolonged stagnation is a distinct possibility.

\section{Social and political risks}

MOST OF THE COUNTRIES IN TRANSITION are democracies, so risks to political stability are relatively low; and EU membership as well as the EU accession process also have a stabilizing effect. Countries that are less integrated and less democratized may experience more political instability. Social unrest has been rather rare in the last twenty years or so, in part because labor unions tend to be weak. Currently, however, populism is on the rise, and may change the political landscape in the medium run. There are two risks to overall stability (more in Gligorov et al. 2009).

The first is that financial systems may yet collapse, which would have significant social and political consequences. The

GROWTH IS DISAPPEARING

continued on page 24 
response. Some of the emerging upside risks included high nominal and real wage demands and settlements, a turnaround in the international oil price, stubbornly high food price inflation despite a significant decline in agricultural commodity prices, and high rates of increases in administered prices. These factors also contributed to deteriorating inflation expectations.

The monetary policy stimulus was complemented by a contracyclical fiscal policy. South Africa was in the fortunate position of having sufficient fiscal space-a result of past prudence - to use fiscal policy in a manner that would not raise questions about sustainability. It is generally agreed that fiscal stimuli in such circumstances should be reversible, with an emphasis on increasing growth-enhancing capital expenditure. The problem is that capital expenditure takes time to implement and so may not be well-suited for cyclical purposes. It was therefore fortuitous that government had embarked on a large-scale infrastructure expenditure program during the earlier part of the decade (including road and rail infrastructure, telecommunications, and more recently electricity generation), and much of this was coming to fruition at a time when most needed from a cyclical perspective. Government and state-owned enterprise expenditure on infrastructure is expected to average 9.7 percent of GDP over the next three years compared with 4.5 percent of GDP in 2005/06. The public sector borrowing requirement is now expected to increase to 7.5 percent of GDP in $2009 / 10$ before moderating to 5.3 percent by $2011 / 12$. These demands on the capital markets are sustainable because government debt to GDP is currently a modest 22 percent.

There was also direct stimulus through the budget. The government had budgeted for a surplus of 0.6 percent for the 2008/og fiscal year, and with declining tax receipts the outcome was a deficit of 1.2 percent. As a result of the slowing economy and a discretionary fiscal stimulus, a deficit of 3.9 percent of GDP was budgeted for the 2009/10 fiscal year. It is estimated that about half of this increase was due to lower expected tax receipts, implying an expenditure stimulus of some 2 percent of GDP. More recently the minister of finance noted that tax revenues are likely to be somewhat lower than anticipated, and a higher deficit outcome is likely. However the government has projected deficits for the next two financial years to decline to 3.1 and 2.3 percent of GDP respectively.

South Africa has not been spared from the impact of the global crisis. However its policy response should to some extent help to contain the contraction. Some internal and external developments indicate that the worst may be over. Portfolio capital inflows have resumed; the rand has appreciated to almost pre-crisis levels; commodity prices have recovered from their lows, although still significantly below their highs of last year; and most leading indicators show that positive growth should be achieved during the latter part of this year. Nevertheless the recovery is likely to be slow and hesitant, and dependent to a significant degree on the nature and speed of the global recovery.

Brian Kahn is Head of Research and Policy Development at the South African Reserve Bank.
GROWTH IS DISAPPEARING

continued from page 21

level of integration and interconnectedness of the financial system in the EU and in the transition countries would make such a crisis even more devastating then the current one. This is why the International Monetary Fund (IMF) has been called back to support global financial stability-to bail out the banks in effect. It can be expected that many countries in transition will end up with stand-by agreement before this crisis is over. In addition, the IMF is supporting the so-called Vienna Initiative, which is a commitment by the banks in countries that have an IMF program to keep their credit exposure at existing levels, which should help the process of orderly deleveraging. However, in the event of mishaps, financial failure would be transmitted through the interconnected banking system quite quickly (Arvai, Driessen, and OtkerRobe 2009).

The other risk is that these economies may experience stagnation in the medium run. That will have serious consequences for labor markets. Employment will decline anyway and slow growth will accentuate the already existing structural imbalances in these markets (high unemployment, significant segmentation, low employment), possibly leading to social problems and to growing populism. There is little that the EU can do to address that eventuality, short of engineering a strong recovery with strong import demand, which is not something that is being forecasted at the moment.

\section{Conclusion}

THE NEOGLASSICAL MODEL OF GROWTH in the CESE has been disrupted by the current crisis and it is not certain that it can be revived in the medium run. In addition, there are still significant risks that crisis may become even worse, especially if the process of deleveraging does not proceed in an orderly manner. Switching to the alternative growth model based on higher domestic savings would be difficult and would depend on the recovery of EU demand for exports from countries in transition. If that does not happen either, the return to convergence growth rates may prove problematic in the medium run.

Vladimir Gligorov is Senior Researcher at The Vienna Institute for International Economic Studies.

\section{References}

Arvai, Zsofia, Karl Driessen, Inci Otker-Robe (2009), "Regional Financial Interlinkages and Financial Contagion Within Europe," IMF Working Paper WP709/6.

European Commission (2009), "Impact of Current Economic and Financial Crisis on Potential Output," European Economy, Occasional Papers 49 (June).

Gligorov, V. et al. (2009), "Final Report on Financial Risks in Candidate and Potential Candidate Countries," draft paper.

Gligorov, V., J. Poeschl, S. Richter et al. (2009); "Where Have All the 'Shooting Stars' Gone?," wiiw Forecast Report 4 (July). 